\title{
Hubble Space Telescope Thermal Blanket Repair Design And Implementation
}

\author{
Wes Ousley \\ NASA Goddard Space Flight Center \\ Joseph Skladany \\ Orbital Sciences Corporation \\ Lawrence Dell \\ Lockheed Martin Technical Operations
}

\begin{abstract}
Substantial damage to the outer layer of Hubble Space Telescope (HST) thermal blankets was observed during the February 1997 servicing mission. After six years in LEO, many areas of the aluminized Teflon $^{\circledR}$ outer blanket layer had significant cracks, and some material was peeled away to expose inner layers to solar flux.
\end{abstract}

After the mission, the failure mechanism was determined, and repair materials and priorities were selected for follow-on missions. This paper focuses on the thermal, mechanical, and EVA design requirements for the blanket repair, the creative solutions developed for these unique problems, hardware development, and testing.

\section{INTRODUCTION}

The Hubble Space Telescope (HST) was launched in April 1990 into a low-Earth orbit, and has spent its scientifically productive on-orbit lifetime between $550 \mathrm{~km}$ and $620 \mathrm{~km}$ altitude. Thermal blankets on the telescope are Multi-Layer Insulation (MLI) with an outer layer of aluminized Teflon $^{\star}$, a common design flown on dozens of spacecraft. During the HST First Servicing mission (SM1) in December 1993, no damage to thermal blanket materials was observed. The Teflon layer showed a small reduction in specular reflectivity on the Sun side of the telescope, but the material maintained its mechanical integrity, and the flight crew did not observe any reduction in flexibility.

\section{Second Servicing Mission Activities}

In February 1997, significant degradation of the outer layer of the telescope thermal blankets was seen during the HST Second Servicing Mission (SM2). Many àreas were substantially cracked, and three large areas of outer layer peeled away from the rest of the blanket. Figure 1 shows the largest tear, which exposed the aluminized surface of the next layer of blanket to the space environment. Quick calculations showed that any exposed inner layer would be about $200^{\circ} \mathrm{C}$ when in direct sunlight, and heat input through the blanket to the structure could be 50 watts per square meter of exposed surface.

A tiger team was convened to quickly determine what the astronaut crew could do to mitigate any potential negative effects on the observatory. Damage assessment was performed, including camera surveys of the telescope, review of flight temperature history of affected areas, thermal analysis, and evaluation of contamination and structural effects. Materials available to the crew (wire, cord, tools, tape, patch material, etc.) were collected and evaluated for use in repair activities. Repair areas were prioritized, and procedures were developed for the crew to assemble patches in the crew cabin and install the patches on the telescope. Veteran astronauts checked out the assembly procedures on a table, then evaluated the installation procedures on detailed telescope mockups. Procedures were uplinked to the flight crew, and they performed the patch assembly and installation during the following two days.

As a result of these efforts, a total of five areas were patched by the flight crew. Two large areas on the HST light shield (see Figure 2) were covered with new material. In addition, two electronics bay doors were 
patched, and another bay door was strung with wire to prevent peeling of its outer layer.

\section{Failure Review Board}

After the mission, a Failure Review Board (FRB) was convened to investigate the HST blanket materials. Over the following year, this board developed maps of visibly damaged areas, found MLI damage mechanisms, recommended priorities for future MLI repairs, and selected replacement materials. The FRB determined that the outer layer was embrittled by the space environment (especially charged particles) and fatigued by thermal cycling, leading to a weakened material that cracked easily. Small cracks and manufacturing cuts tended to propagate larger cracks, which led to the peeling away of the outer layer in a few areas'.

The areas most threatened by the MLI damage were the electronics bays on the sun side of the telescope, since some boxes in these bays had previously approached hot limits. The large tears and numerous small cracks on the sun side of the forward shell and light shield, along with the prospect of further degradation, led the FRB to recommend that these areas be repaired during the HST Third Servicing Mission (SM3). In both cases, the underlying MLI was not degraded, so installation of a new outer layer with proper material properties was determined to be adequate to restore the telescope thermal configuration.

Candidate materials were selected by the FRB and subjected to a series of simulated space exposures including $x$-rays, ultraviolet, charged particles, thermal cycling, and atomic oxygen. Exposures were 10-year equivalent doses to verify material endurance. Following testing, two materials were selected for use in repair task applications ${ }^{2}$.

Material for the New Outer Blanket Layer (NOBL) to be installed on sun-facing electronics bays (Figure 2) required very low end-of-life solar absorptivity $(\alpha)$ and high emissivity $(\varepsilon)$ to minimize hot-case temperatures in the bays. The NOBL material selected was $0.1 \mathrm{~mm}$ stainless steel coated with vapor deposited silver, with an overcoat of $\mathrm{SiO}_{2} / \mathrm{Al}_{2} \mathrm{O}_{3}$. This coating had been flight qualified $^{3}$, is extremely durable, and has the thermal properties (end-of-life $\alpha / \varepsilon=.13 / .67$ ) to meet the strict requirements of the electronics bays.

The Shield/Shell Replacement Fabric (SSRF), for installation on the sun side of the forward shell and light shield, required flexibility for compact stowage and quick deployment to cover this $40 \mathrm{~m}^{2}$ area. All the SSRF requirements were met with a composite of $0.13 \mathrm{~mm}$ aluminized Teflon ${ }^{\infty}$ bonded to Nomex ${ }^{(9)}$ scrim. This material had adequate thermal properties, and the scrim acted as a rip-stop to prevent the crack propagation seen on the original HST material.

\section{FLIGHT HARDWARE DESIGN}

The primary requirement for the repair materials was to protect the telescope from thermal extremes caused by mechanical failure of the MLI outer layer. Allowable thermal properties of the NOBL were restricted by electronics bay thermal requirements, and the configuration of the bays allowed the stiff steel foil material to be used. Extensive thermal analysis was performed to evaluate NOBL design options and verify thermal effects (see below). Thermal properties of the SSRF were not so restricted, so a much more flexible material was chosen despite its higher solar absorptivity. With the limited EVA time available on a busy repair mission, installation speed and simplicity were also critical design factors.

Many other requirements were imposed by telescope needs and astronaut interfaces:

- A 10-year operational life after installation, from the servicing mission until projected HST end-of-life

- Stowed to survive launch and be easily retrieved for installation

- Modular design and installable in any order, for flexibility in mission planning

- Alignment features and installation guides, since most repair areas were never designed for servicing.

- Coverage of $90 \%$ for non-radiator surfaces of each electronics bay door, and $70 \%$ for the sun-facing light shield/forward shell area.

- Installed hardware should have no impact on HST operations or other EVA activities, so cutouts were provided for radiators, handrails, foot sockets, mechanisms, etc.

- Removable, with minimum attachment points to simplify installation.

- Must survive landing loads after installation, for HST retrieval safety

\section{Design of Electronics Bays Repair}

Seven NOBL covers were fabricated for installation on electronics bays. The steel foil selected for the NOBL's was not very flexible, but the design of the bays permitted the use of a stiff frame to support the foil and aid in installation. The NOBL's had cutouts to give door radiators a direct view to space, and high-emissivity tape was applied to the inside surface to reduce solar heating during transport and increase radiative throughput after installation.

Of the six bays on the sun side of HST (Bays $5-10$ as shown in figure 2$)$, four had flat doors $(5,7,8,10)$. The flat door NOBL material was bonded to a $1 \mathrm{~mm}$ steel support frame conforming to the door bevel and shaped 
like a picture frame (figure 3 ), providing stiffness to ease handling, allow for easy mounting, and maintain the proper shape after installation. Another flat door NOBL was fabricated to reduce heat transfer from Bay 1 because a planned computer upgrade would result in a large power reduction in that bay. These covers were to be installed with expanding plugs inserted into four $32 \mathrm{~mm}$ vent holes in each door. A plug (figure 4) was inserted into each vent hole and the handle pivoted down $90^{\circ}$, operating a cam and locking the plug in place. Metallic "fingers" were flexed radially outward by sliding wedges. The "fingers" contacted the door vent spool, providing secure attachment. A flange on the vent plug held the NOBL sheet securely against the door.

The doors on Bays 6 and 9 have a curved cross-section to accommodate the reaction wheels. The NOBL foil was bonded to a $1 \mathrm{~mm}$ steel support frame that was curved to conform to the door surface (figure 5). The vent holes on these doors were not easily accessed (as on the flat doors) because the holes in the door blankets were smaller than the vent holes. The NOBL's for these doors would be clipped to the doorstop and doorknob stem of each respective door, as shown in figure 5 . This turned out to be a quicker and simpler installation than that of the flat doors using the vent plugs, but the flat doors did not have a similar doorstop/doorknob configuration.

\section{Electronics Bays Thermal Analysis}

Thermal analysis was performed to tailor each NOBL to the requirements of its electronics bay. The detailed HST Support Service Module Equipment Section (SSM ES) thermal math model was used to determine component temperatures for the baseline design and to evaluate design modifications with the NOBL installation. Figure 6 shows a cross section of the SSM ES with the bays identified along with the components in each bay.

Bay 8 and 10 components had reached temperature limits during the high solar flux period (winter) and high duty cycle conditions. Bay 5 transmitter components were scheduled for higher duty cycles after SM3 and were predicted to reach their hot limit in End-of-Life (EOL) hot conditions. In Bay 1, the Advanced Computer (HST486) with lower power would result in lower Data Management Unit (DMU) temperatures and higher heater duty cycles. Detailed SSM ES thermal analyses were conducted to determine thermal design modifications to provide additional heat rejection for bays 5,8 , and 10 and to reduce bay 1 heat rejection. In addition, the model was used to determine the thermal impact of not repairing the door MLI outer layer, which would result in exposing the underlying double aluminized Kapton layer (DAK) to the environment. The DAK has a high ratio of solar absorptance to infrared emittance $(\alpha / \varepsilon=.14 / .04)$, which in direct sun has a temperature around $200 \mathrm{C}$ and can input $50 \mathrm{~W} / \mathrm{m}^{2}$ to interior structures.

Bay 1 Thermal Study: This object of this study was to maintain Data Management Unit (DMU) temperature levels despite a large Bay 1 power reduction. The HST486 computer planned to be installed during SM3 dissipated about 30 watts, considerably less than the 119 watts dissipated by the old DF224/COP computer. Performance of the DMU was very sensitive to temperature, and the baseline temperature range provided optimum characteristics. To avoid increasing heater power consumption, it was decided to add an external MLI blanket or a shield in the form of a NOBL cover. Figure 7 presents the Bay 1 configuration with the DMU mounted on the internal door surface and the DF 224 computer mounted to structure off the tunnel. Figure 8 displays the DMU and HST486 computer temperatures and heater power requirements comparing the baseline thermal design with the DF 224/COP; an unchanged thermal configuration with a 35 watt HST486 computer; and a NOBL cover over $57 \%$ of the door with a 22 watt HST486 computer. The current DF 224/COP resulted in DMU temperatures between $-2^{\circ} \mathrm{C}$ and $4^{\circ} \mathrm{C}$ with no heater power required. With the change to the HST486 computer at 35 watts, the DMU temperatures drop to $10^{\circ} \mathrm{C}$ to $-7^{\circ} \mathrm{C}$. The Bay 1 NOBL covering $57 \%$ of the door area with the HST486 at 22 watts results in DMU temperatures of $-2^{\circ} \mathrm{C}$ to $3^{\circ} \mathrm{C}$.

Bay 5 Thermal Study: The Bay 5 thermal study was conducted to help accommodate the higher transmitter duty cycles expected after SM3. Figure 9 presents the Bay 5 configuration with the transmitter components mounted on the internal door surface on an aluminum plate, two tape recorders mounted to structure off the tunnel, and the external bay door MLI pattern with $13 \%$ silver Teflon ${ }^{*}$ radiators. Figure 9 also contains results from the MLI removal study performed with powers representative of one Solid State Recorder (SSR) and one tape recorder (ESTR). MLI removal before NOBL installation yielded a hot case temperature reduction of approximately $7^{\circ} \mathrm{C}$ for the transmitters, and about $5^{\circ} \mathrm{C}$ for SSR-1. The cold case heater power increase was 10 watts for the communications tray and 3 watts for ESTR3. Bay $5 \mathrm{MLI}$ removal was recommended to avoid reaching the transmitter temperature limits at end-of-life in hot conditions, with the expected increase in science data volume.

The effect of not repairing the outer layer of MLI is also shown on Figure 9 for four cases. With only the Bay 5 MLI outer layer of DAK, the transmitter temperatures increased to $16^{\circ} \mathrm{C}$ (a rise of $19^{\circ} \mathrm{C}$ ) and the recorder temperature increased to $23^{\circ} \mathrm{C}$. With a $30^{\circ}$ roll, the recorder reached $40^{\circ} \mathrm{C}$, close to its $43^{\circ} \mathrm{C}$ temperature limit. The condition with all $+\mathrm{V} 3$ bays DAK and a $30^{\circ}$ roll 
would result in the SSR-1 far exceeding its $43^{\circ} \mathrm{C}$ limit, reaching approximately $57^{\circ} \mathrm{C}$.

BAY 6 and 9 Thermal Study: Figure 10 presents the Bay 6 and 9 configuration with the two Reaction Wheel Assemblies (RWAs) in each bay. The Bay 6 door was $88 \% \mathrm{MLI}$ covered, and the Bay 9 door had $81 \% \mathrm{MLI}$. (Bay 9 has a larger radiator because its adjacent bays are warmer.) RWA temperatures for the four cases studied are shown in Figure 10. The only limit exceedances occurred when all the $+V 3$ bays are not repaired, and the $\mathrm{MLI}$ outer layer was DAK. With a $30^{\circ}$ roll to the sun added on, the RWA temperatures got to $51^{\circ} \mathrm{C}$ (Bay 6) and $50^{\circ} \mathrm{C}$ (Bay 9), exceeding the $49^{\circ} \mathrm{C}$ limit. If $+V 3$ NOBL installation were postponed, there could be roll constraints as the MLI DAK becomes exposed.

BAY 7 Thermal Study: Figure 11 presents the Bay 7 configuration with boxes mounted on the door internal surface and the tunnel structure. The Bay 7 door has always been completely covered with an MLI blanket. The impact of individual Bay $7 \mathrm{MLI}$ with a DAK outer layer was large (about $20^{\circ} \mathrm{C}$ ) since Bay 7 was directly in the sun. With the +V3 bays all DAK, three of the four boxes approached their $60^{\circ} \mathrm{C}$ limits. Adding a $30^{\circ}$ roll would result in the GEA reaching its $60^{\circ} \mathrm{C}$ limit.

Bay 8 Thermal Study: The object of this study was to increase the bay heat rejection. The ESTR2 tape recorder has approached temperature during high solar flux and high duty cycle periods. Figure 12 shows the Bay 8 configuration with its boxes mounted on the door internal surface and the tunnel structure, and the Bay 8 door with $100 \% \mathrm{MLI}$ blanket. Figure 12 also presents the Bay 8 thermal analysis results comparing the baseline MLI with aluminized Teflon ${ }^{\oplus}(\alpha / \varepsilon$ ratio of $0.22 / 0.78)$ and the NOBL cover ( $\alpha / \varepsilon$ of $0.13 / 0.67$ ) for the hot cases at EOL. The addition of the NOBL cover with the lower $\alpha / \varepsilon$ ratio reduced the Bay 8 maximum temperatures by about $4^{\circ} \mathrm{C}$. Removing the MLI from the door only reduced the maximum temperatures by $1^{\circ} \mathrm{C}$ to $2^{\circ} \mathrm{C}$ since the bay door outer surface has a low emittance. The cold case heater power increased to 28 watts with MLI removal. For these reasons, Bay $8 \mathrm{MLI}$ blanket removal was not planned.

The impact to Bay 8 of not repairing the MLI outer layer is also presented on Figure 12. With the Bay 8 door MLI DAK outer layer, the Tape Recorder temperature increased to $35^{\circ} \mathrm{C}$. With all the $+\mathrm{V} 3$ bays $(5$ to 10$)$ door $\mathrm{MLI}$ outer layer of DAK, the recorder $\left(50^{\circ} \mathrm{C}\right)$ exceeded its $43^{\circ} \mathrm{C}$ limit, and the PSEA $\left(60^{\circ} \mathrm{C}\right)$ exceeded its $54^{\circ} \mathrm{C}$ limit.

Bay 10 Thermal Study: The object of this study was to increase the bay heat rejection. During high tasking periods for the Scientific Instrument Command and Data Handling system (SI C\&DH), high box temperatures have occurred, so science mission schedules were reviewed for potential problems. If the ACS (Advanced Camera for Surveys) were to be added as planned during a future servicing mission, there would be higher SI C\&DH duty cycles, thus hotter conditions. Figure 13 shows the Bay 10 configuration with the SI C\&DH tray mounted on the door internal surface and four boxes mounted to the tunnel structure. The Bay 10 door with two MLI blankets and $22 \%$ door area silver Teflon ${ }^{\circ}$ radiator is also shown. As presented in Figure 13, with the Bay 10 door MLI outer layer of DAK, the SI C\&DH component temperatures increased to $27^{\circ} \mathrm{C}$ for the memory units and to $41^{\circ} \mathrm{C}$ for the SDF with current power levels. With a $30^{\circ}$ roll with individual Bay $10 \mathrm{MLI}$ outer layer of DAK, the temperature of the Memory Units increases beyond its $41^{\circ} \mathrm{C}$ limit to $45^{\circ} \mathrm{C}$. With the higher SI C\&DH duty cycles forecast, further increases in Memory Unit and SDF temperatures would be expected. With the NOBL cover installed and both MLI blankets removed, maximum temperatures were reduced by $5^{\circ} \mathrm{C}$, and no heater power was required in the cold case. Since NOBL installed over the MLI produced no benefit, MLI removal followed by NOBL installation was recommended.

Bays 2, 3, 4: Additional SSM ES thermal studies were conducted assuming that door MLI blankets on anti-sun side bays 2, 3, and 4 had an outer layer of DAK. All component temperatures remained well within limits, without large changes, so no NOBLs were recommended for these bays. It may become necessary to provide a NOBL cover for Bays 2 and 3 at some future date to maintain positive battery temperature control. Battery replacement is being considered for SM4 and bay thermal design modifications may be incorporated with the change.

\section{Forward Shell and Light Shield (FS/LS) Design}

The sunward side of the FS/LS comprises a $40 \mathrm{~m}^{2}$ area on the 3m-diameter telescope tube. Seven rolls of scrimmed Teflon material were designed to cover most of this area without affecting deployables or blocking access to handrails, foot sockets, and other components. Figure 14 shows the layout of the installed material. The SSRF pieces were fabricated on a detailed HST surface simulator to allow precise cutouts and aid in location of attachments. Clip/cable attachment assemblies were attached to each SSRF, and adjusted to their predicted length. After fabrication, each SSRF piece was rolled up for compact stowage on the Shuttle (Figure 15).

Clips with adjustable cables were installed on the material to allow quick and flexible attachment (Figure 16). The Teflon coated cable with clips would attach SSRFs to hard points (handrails, brackets, struts, etc.) Each clip would be fed through or around a feature and attached back to the cable. Grommets allow the wire to 
pass through and support the material without tearing it, with cord-locks used for length adjustment. Altachment between adjacent SSRFs would utilize Velcro"

\section{HARDWARE DEVELOPMENT AND FLIGHT PREPARATIONS}

High fidelity mockup models of the exterior surfaces of the SSM bays, forward shell, and light shield based on flight drawings and in-flight photographs were fabricated early in the design process. These mockups were used as templates for detailed design and fabrication of the repair hardware. Test articles representing NOBLs and SSRFs were constructed for design evaluations and modified as the design evolved. Testing by engineers and flight crew at the NASAJJohnson Space Center Neutral Buoyancy Lab (NBL) showed that additional handles, labels, and tether points were needed to satisfy EVA handling and safety concerns. Maps and alignment marks were added to the SSRFs during crew evaluations and training sessions to ensure installation accuracy and speed.

\section{Installation Plan}

Detailed installation procedures for NOBLs and SSRFs were developed and timelined during NBL training. Prior to installation of a NOBL, patches installed by the SM2 crew in 1997 had to be removed to preserve bay door operations, and thermal requirements specified removal of some electronics bay MLI pieces. Practice at the NBL with the SM3 flight crew produced a streamlined, simple plan for the Bay $5-10$ NOBL task:

- After previous Bay 5 operations, remove Bay $5 \mathrm{MLI}$ (10 minutes at NBL)

- Retrieve Bay 5 and 6 NOBLs and install ( $30 \mathrm{~min}$ )

- Remove SM2 patches from Bays 7 and $8(20 \mathrm{~min})$

- Retrieve Bay 7 and 8 NOBLs and install (30 min)

- Remove SM2 patches from Bay 10 (20 min)

- Retrieve Bay 9 and 10 NOBLs and install $(30 \mathrm{~min}$ )

- Installation time $90 \mathrm{~min}$; total task $140 \mathrm{~min}$

To install the SSRF pieces on the telescope, one crewmember (on the Shuttle arm) would clip the roll to a handrail or other feature, then unroll the piece in stages. The other crewmember (free-floater) would assist with clip attachments to HST structures and Velcro ${ }^{\circ}$ attachment to adjacent SSRFs. The SSRF pieces covering the lower forward shell (numbers 5, 6, 7 in Figure 16) were to be installed first since these areas covered the telescope mirror and lower metering structure. The other four SSRFs would be installed left to right, in numerical order. The predicted task time for SSRF installation was 3 hours and 40 minutes.

\section{Flight Closeout}

Final fit checks, functional testing, adjustments, and photo documentation of the deployed NOBLs and SSRFs were performed on the high-fidelity mockups. Repair hardware items were stowed in their flight carriers at the launch site. Final crew familiarization, photo documentation, and closeout occurred in August 1999 for the STS-103 launch scheduled October 14.

\section{Third Servicing Mission Activities}

After launch delays to close out Shuttle wiring and other safety issues, a new launch window was established in December 1999. Weather delays pushed the launch beyond the last day in the window to avoid any $Y 2 K$ postlanding complications. Because spacecraft failures had stopped HST science operations, and SM3 was needed to restore the telescope, the mission was launched with the EVA days reduced from four to three. All required mission tasks were performed successfully, but time permitted only three of seven NOBLs and no SSRFs to be installed. Forward shell and light shield MLI conditions had not degraded significantly since the Second Servicing Mission, so the SSRF material installation remained an optional task.

The NOBL for Bay 1 was installed as planned during the second EVA following the computer changeout. This activity took 16 minutes, compared to the predicted 20 minutes. On the third and last EVA day, difficulties with earlier tasks reduced the available time to the point where only one pair of NOBLs could be installed. Thermal and operational considerations (discussed in the Thermal Analysis section) pointed to Bay 10 as the highest priority, so the Bay 9 and 10 NOBL pair were installed following removal of the Bay 10 patches and MLI blankets. Planned at 50 minutes, this activity took 75 minutes because the insulation was difficult to remove.

The Bay 1 NOBL design met its thermal design goal, maintaining DMU temperature level despite the 90-watt power reduction on the adjacent computer. The DMU temperature has averaged about $-3^{\circ} \mathrm{C}$, within its premission range of $-4^{\circ}$ to $+2^{\circ} \mathrm{C}$.

Bays 9 and 10 have seen some post-mission temperature reduction, but precise solar/attitude timeline data have not been correlated with pre-mission thermal performance.

\section{CONCLUSIONS}

Hardware for on-orbit MLI repair of the HST was successfully developed, tested, and installed. 
Items installed on orbit proved the adequacy of the hardware design and EVA preparations.

Thermal design improvements included in the electronics bays repair tasks successfully lowered box temperatures on the sun side of the telescope, and maintained the $\mathrm{DMU}$ box at its desired operating temperature

\section{Acknowledgements}

\section{REFERENCES}

1. Townsend J A, Hansen P A, Dever J A, de Groh KK, Banks B A, Wang $L$, and He C: HST metallized Teflon $^{\circledR}$ FEP thermal control materials: on-orbit degradation and post-retrieval analysis, High Performance Polymers, v 11, no 1, March 1999

2. Townsend $J$ A, Hansen $P$ A, McClendon $M W$, de Groh K K, and Banks B A: Ground-based testing of replacement thermal control materials for the HST, High Performance Polymers, v 11, no 1, March 1999

3. Triolo J J, Heaney J B, and Hass G: Coatings in Space Environment, SPIE v 121, Optics in Adverse Environments, 1977

\section{ACRONYMS, ABBREVIATIONS}

$\alpha$

COP

DAK

DF224

DMU

$\varepsilon$

EOL

ESTR

EVA

FRB

FS/LS

HST

HST486

JSC

MLI

NASA

NBL

NOBL

RWA
Solar absorptance

Co-processor

Double-aluminized Kapton

Original HST computer

Data Mangement Unit

Infrared emittance

End of life

Original HST tape recorder

Extra-Vehicular Activity

Failure Review Board

Forward shell / light shield

Hubble Space Telescope

Advanced computer for HST

NASAJJohnson Space Center

Multi-layer insulation

National Aeronautics and Space Admin. Neutral Buoyancy Lab (at JSC)

New Outer Blanket Layer

Reaction Wheel Assembly
$\mathrm{SI}$

SI C\&DH

SM

SSMES

SSR

SSRF

STS

$+\sqrt{ } 3$

$-V 3$
Scientific Instrument

SI Command \& Data Handling

Servicing Mission

Support Sys Module Equipment Section

Solid State Recorder

Shield/Shell Replacement Fabric

Space Transportation System

Sun side of HST

Anti-sun side of HST 


\section{DRAFT}
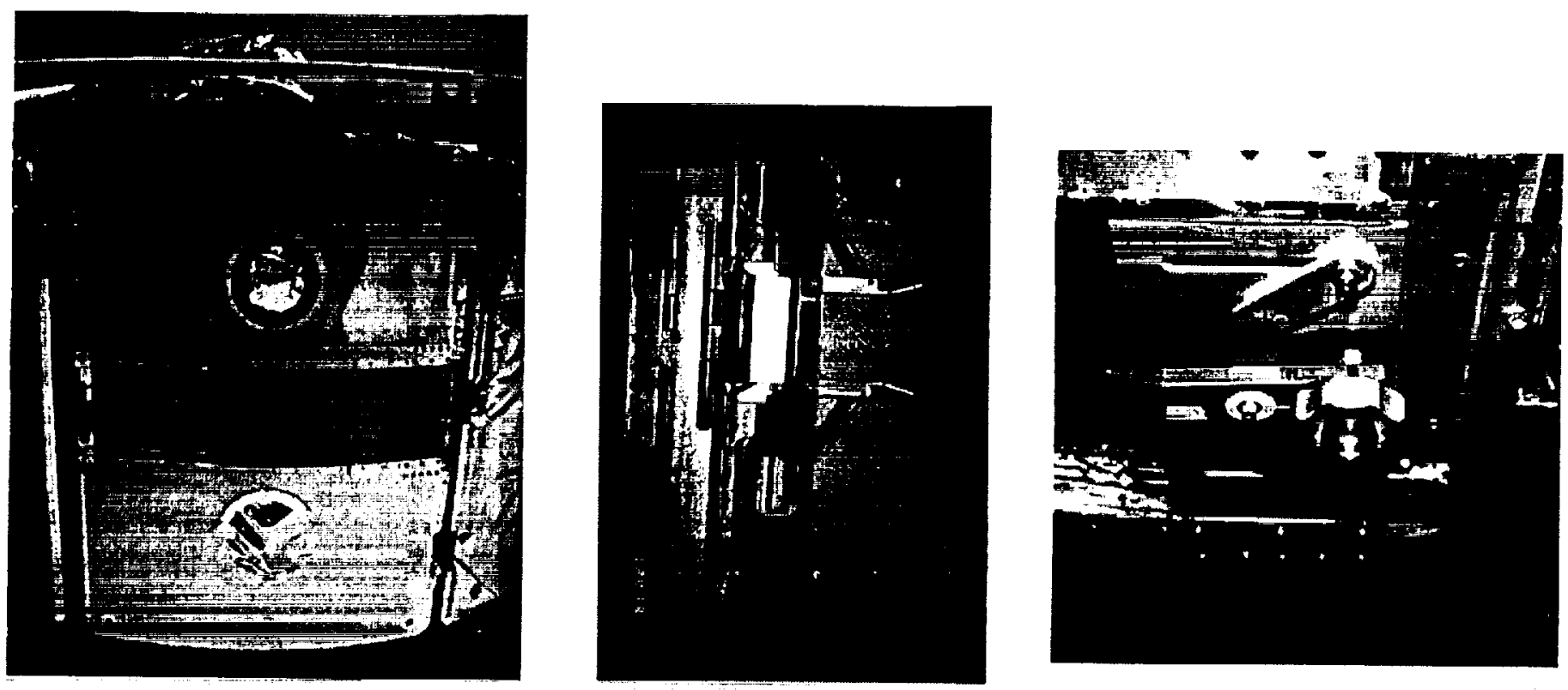

Figure 5 - NOBL curved door, doorstop attachment, doorknob attachment

BAY 7 - MECHANISM CONTROL DN

MCU

SADE (2)

GEA

BAY 6 - REACTION WHEEL RWA (2)

BAY 5 - COMMUNICATIONS

SSA XMTTR (2)

MA XPNDRIXMTR (2)

MA FILTEA (2)

MA OPLXR (2)

FF CIA SW

RF XFR SW (2)

AF SW (2)

RF $M L X A(2)$

GECOROSIL
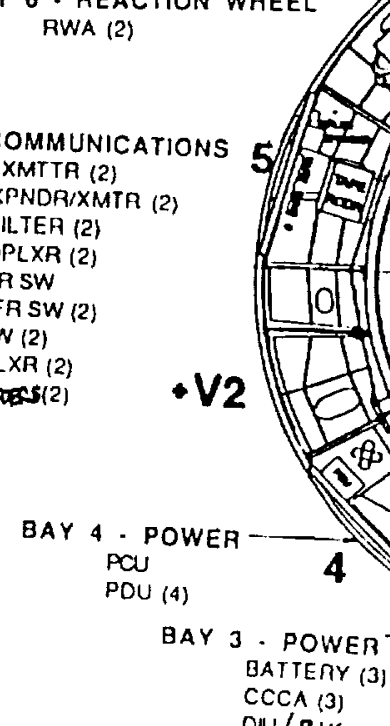
BAY 9 - REACTION WHEEL
RWA 2$\}$

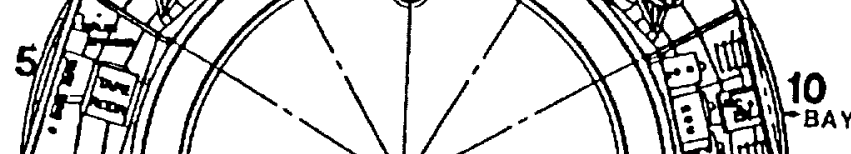
EING CONTAOL AMGA PSEA ICU

DIU/BIK

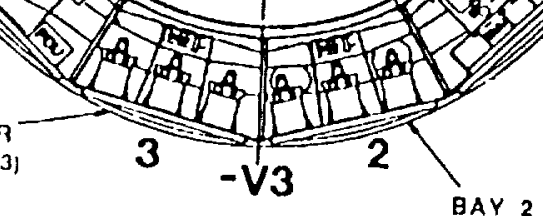

1

1 -BAY 10 - SI CONTROL \& 0 SI C\&DIIANDLING DN RGAECU (3)

LOOXINE SORWABO

POWER

DATTEAY (3)

CCCA (3)

Figure 6 - SSM Electronics Bays Cross Section 


\section{DRAFT}

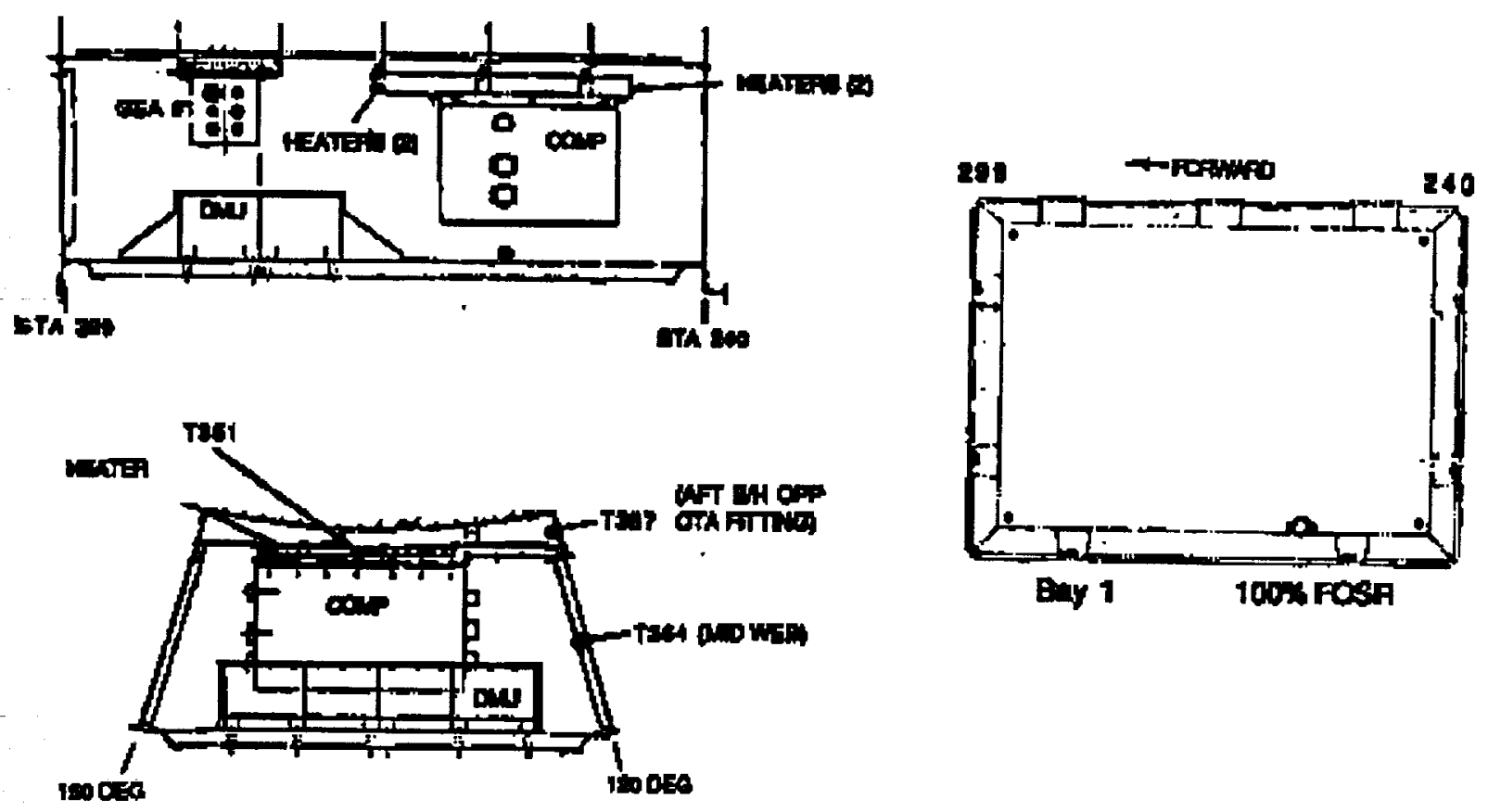

Figure 7 - Bay 1 Configuration

\begin{tabular}{|c|c|c|c|c|c|c|c|}
\hline & \multicolumn{4}{|c|}{ Baseline } & \multirow{2}{*}{\multicolumn{3}{|c|}{$\begin{array}{c}\text { NOBL, High \& back } \\
29.4 \text { w HST } 486 \\
54 \% \text { cover }\end{array}$}} \\
\hline & \multicolumn{2}{|c|}{$\begin{array}{l}119 w \text { DF }-224 \\
100 \% \text { Teflon }\end{array}$} & \multicolumn{2}{|c|}{$\begin{array}{l}35 \text { WST } 486 \\
100 \% \text { Teflon }\end{array}$} & & & \\
\hline Equipment & $\begin{array}{l}\text { Cold } \\
S M 3\end{array}$ & $\begin{array}{l}\text { Hot } \\
\text { EOL }\end{array}$ & $\begin{array}{l}\text { Cold } \\
\text { S M } 3\end{array}$ & $\begin{array}{l}\text { Hot } \\
\text { EOL }\end{array}$ & $\begin{array}{l}\text { Cold } \\
\text { S M } 3\end{array}$ & $\begin{array}{c}\text {-V1 Hot } \\
\text { EOL }\end{array}$ & $\begin{array}{l}-30^{\circ} \text { roll } \\
\text { Hot EOL }\end{array}$ \\
\hline DMU & -1.9 & 4.1 & .9 .6 & -6.6 & -3.0 & 3.5 & 5.6 \\
\hline HST 486 & 18.1 & 21.7 & -8.2 & -7.0 & -8.2 & -3.5 & -1.1 \\
\hline Heater P w r & $0 \mathrm{~W}$ & $0 \mathrm{~W}$ & $5.9 \mathrm{~W}$ & $0 \mathrm{~W}$ & $10.0 \mathrm{~W}$ & $0 \mathrm{~W}$ & $0 W$ \\
\hline
\end{tabular}

Figure 8 - Bay 1 Thermal Study Results 


\section{DRAFT}

\begin{tabular}{|l|c|c|c|c|c|}
\hline COMPONENT & LIMITS & $\begin{array}{c}\text { NOBL, } \\
\text { NO MLI }\end{array}$ & $\begin{array}{c}\text { ONE BAY } \\
\text { DAK ONLY }\end{array}$ & $\begin{array}{c}\text { ROLL, ONE } \\
\text { BAY DAK }\end{array}$ & $\begin{array}{c}\text { ROLL, ALL } \\
\text { BAYS DAK }\end{array}$ \\
\hline Transmitter & $-18 / 60$ & -3 & 16 & 36 & 53 \\
\hline Tape Recorder & $-12 / 43$ & 12 & 23 & 40 & $\underline{57}$ \\
\hline
\end{tabular}
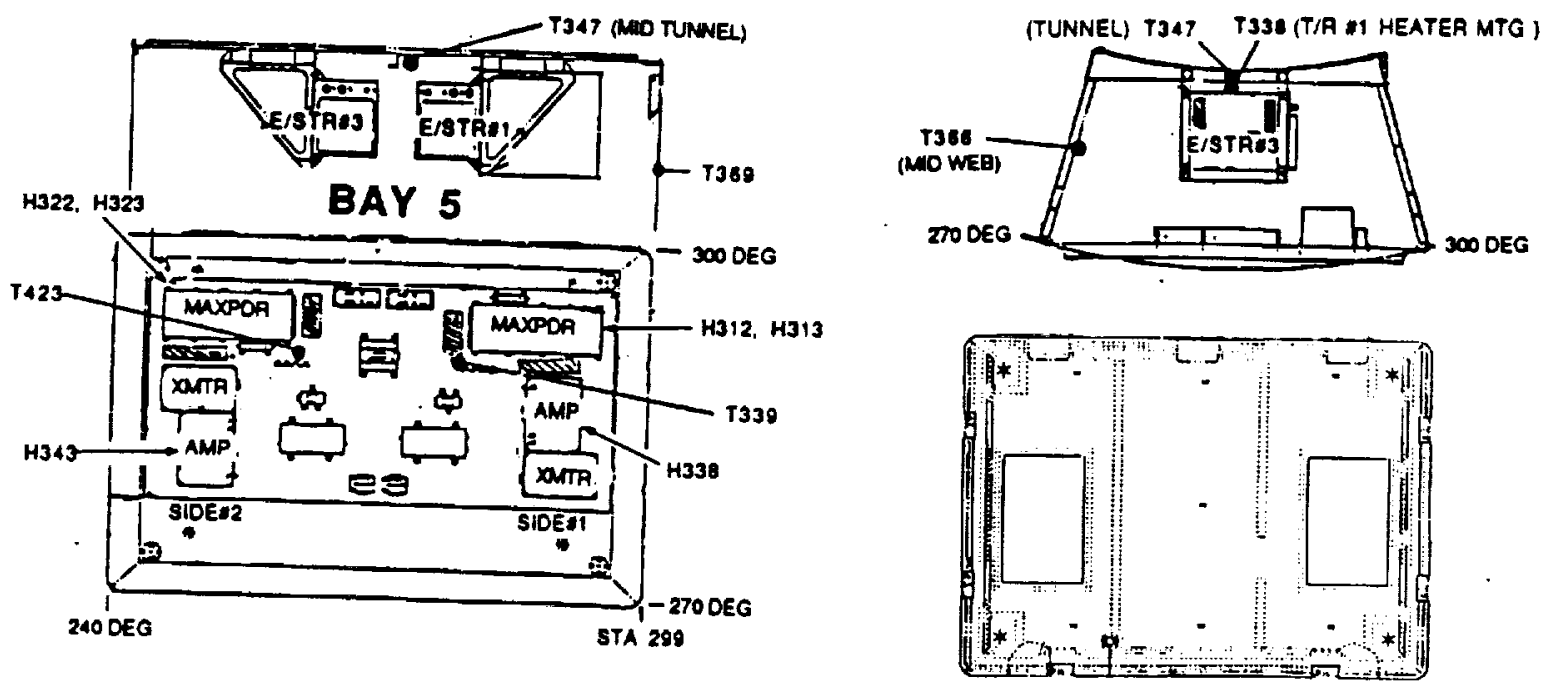

Bay $5 \quad 13 \%$ FOSA, $87 \%$ MLI

Figure 9 - SSM Bay 5 Configuration and Results

Figure 10 - SSM Bay $6 \& 9$ Configuration and Results

\begin{tabular}{|l|c|c|c|c|c|}
\hline COMPONENT & LIMITS & $\begin{array}{c}\text { NOBL, } \\
\text { OVER MLI }\end{array}$ & $\begin{array}{c}\text { ONE BAY } \\
\text { DAK ONLY }\end{array}$ & $\begin{array}{c}\text { ROLL, ONE } \\
\text { BAY DAK }\end{array}$ & $\begin{array}{c}\text { ROLL, ALL } \\
\text { BAYS DAK }\end{array}$ \\
\hline RWA (BAY 6) & $-18 / 49$ & 22 & 25 & 35 & $\underline{\mathbf{5 1}}$ \\
RWA (BAY 9) & $-18 / 49$ & 21 & 27 & 37 & $\underline{\mathbf{5 0}}$ \\
\hline
\end{tabular}

BAY 6
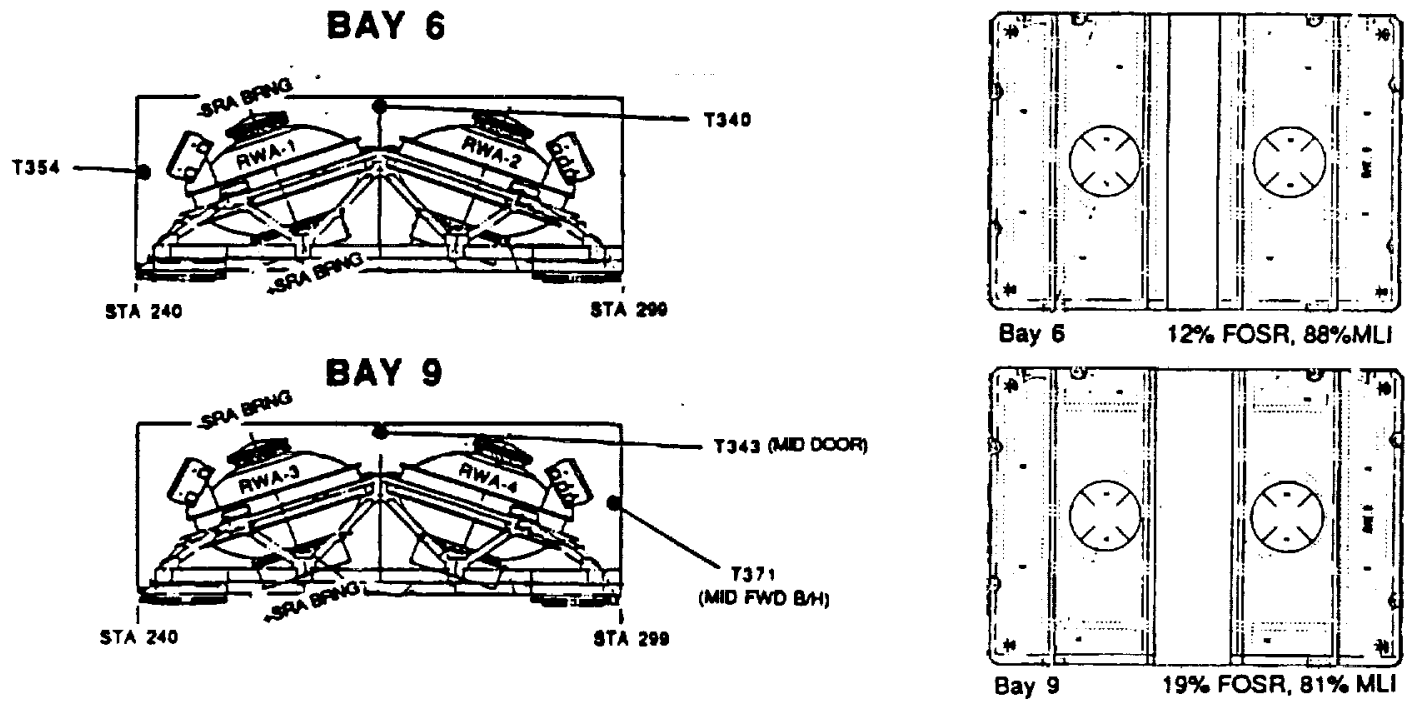


\section{DRAFT}

\begin{tabular}{|c|c|c|c|c|}
\hline COMPONENT & LIMITS & $\begin{array}{c}\text { NOBL, } \\
\text { OVER MLI }\end{array}$ & $\begin{array}{c}\text { ONE BAY } \\
\text { DAK ONLY }\end{array}$ & $\begin{array}{c}\text { +V3 BAYS } \\
\text { DAK MLI }\end{array}$ \\
\hline DIU & $-40 / 60$ & 21 & 37 & 50 \\
\hline GEA & $-29 / 60$ & 22 & 45 & 57 \\
\hline DCE & $-34 / 60$ & 22 & 45 & 56 \\
\hline SADE & $-34 / 60$ & 22 & 44 & 56 \\
\hline
\end{tabular}
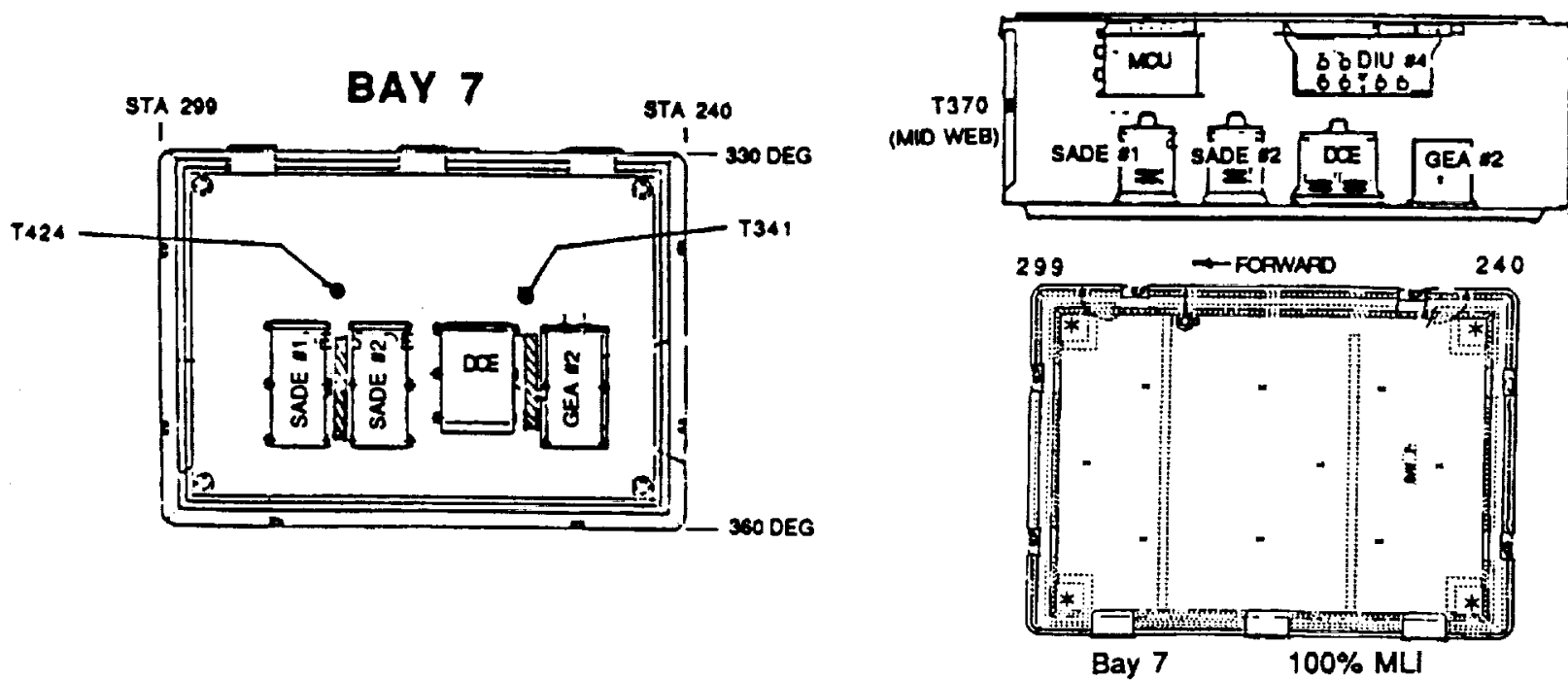

Figure 11 - SSM Bay 7 Configuration and Results

Figure 12 - SSM Bay 8 Configuration and Results

\begin{tabular}{|c|c|c|c|c|c|}
\hline COMPONENT & LIMITS & $\begin{array}{c}\text { NOBL, } \\
\text { OVER MLI }\end{array}$ & $\begin{array}{c}\text { AL TEFLON } \\
\text { OVER MLI }\end{array}$ & $\begin{array}{c}\text { ONE BAY } \\
\text { DAK ONLY }\end{array}$ & $\begin{array}{c}\text { +V3 BAYS } \\
\text { DAK MLI }\end{array}$ \\
\hline Tape Recorder & $-12 / 43$ & 24 & 28 & 35 & $\underline{50}$ \\
\hline PSEA & $-12 / 54$ & 36 & 40 & 46 & $\underline{60}$ \\
\hline ICU & $-30 / 60$ & 18 & 22 & $\frac{43}{38}$ \\
\hline
\end{tabular}
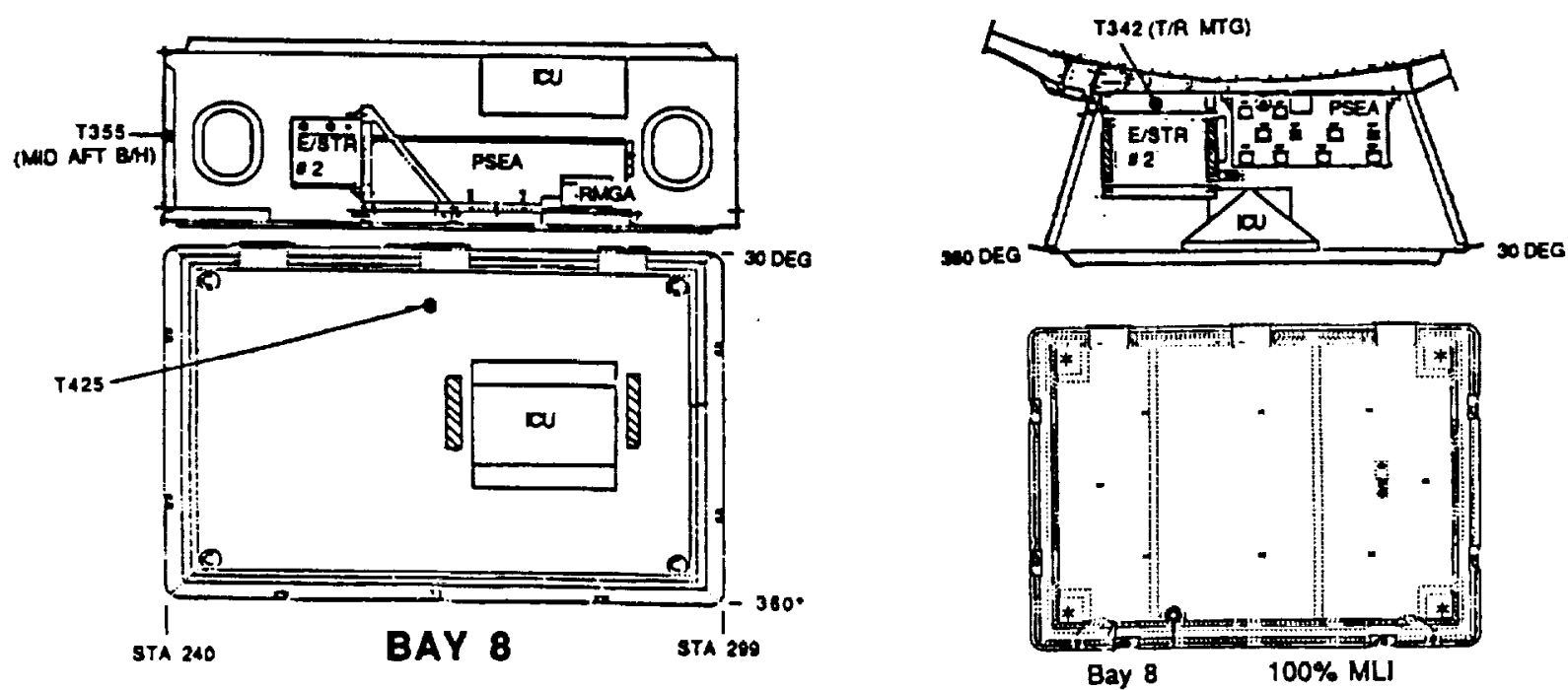
DRAFT

\begin{tabular}{|c|c|c|c|c|}
\hline COMPONENT & LIMITS & $\begin{array}{c}\text { NOBL, } \\
\text { NO MLI }\end{array}$ & $\begin{array}{c}\text { ONE BAY } \\
\text { DAK ONLY }\end{array}$ & $\begin{array}{c}\text { ROLL, ONE } \\
\text { BAY DAK }\end{array}$ \\
\hline $\begin{array}{c}\text { Mem. Units } \\
\text { SDF }\end{array}$ & $-10 / 41$ & 16 & 27 & $\mathbf{4 5}$ \\
\cline { 2 - 5 } ECU & $-10 / 70$ & 32 & 41 & 59 \\
\cline { 2 - 5 } & $-24 / 60$ & 20 & 28 & 44 \\
\hline
\end{tabular}
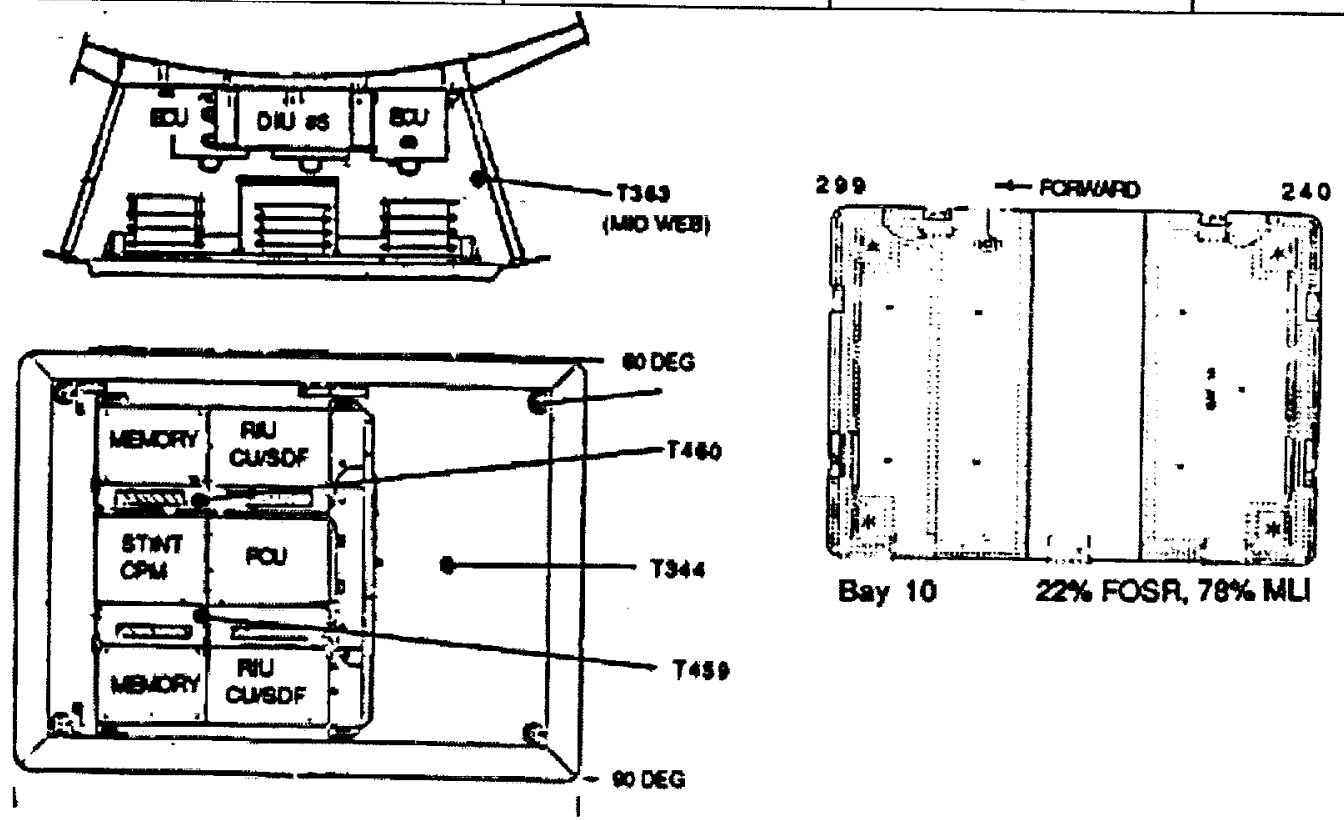

Figure 13 - SSM Bay 10 Configuration and Results

Figure 14 - SSRF layout on HST

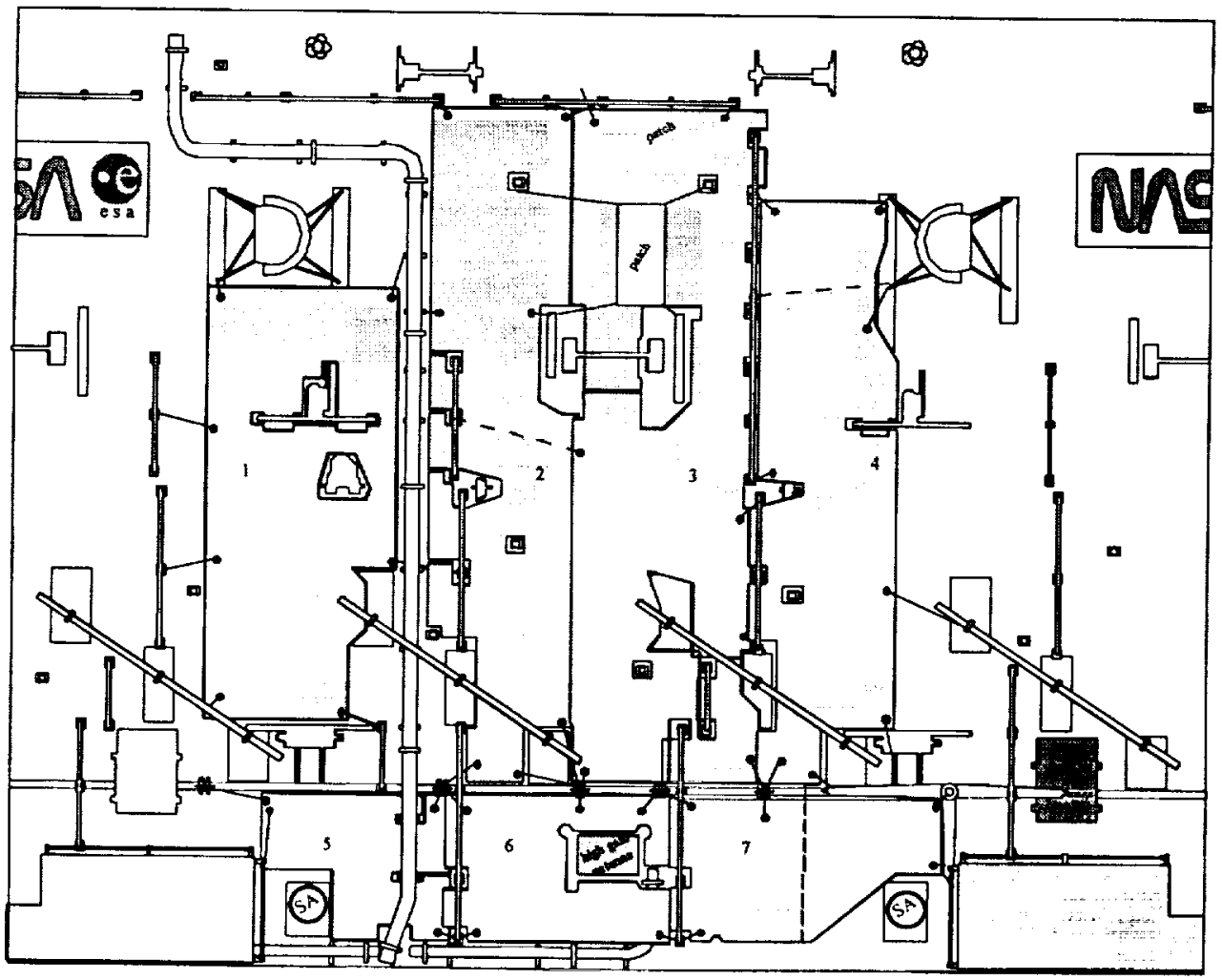




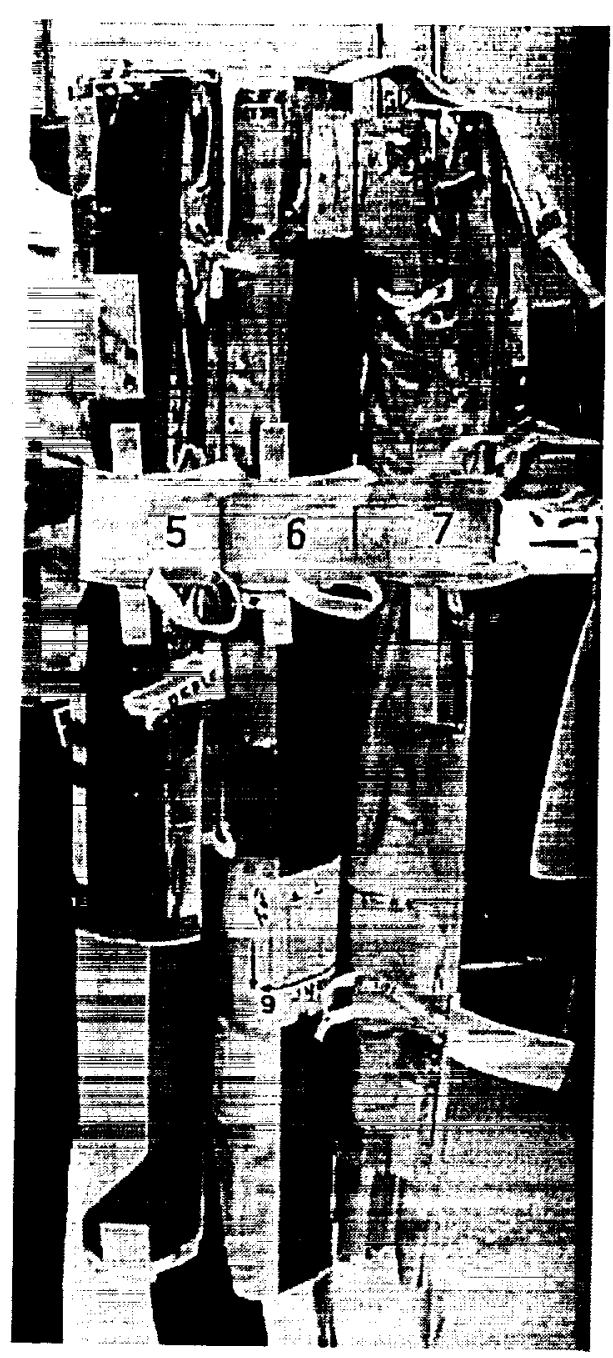

Figure 15 - SSRFs rolled up for stowage

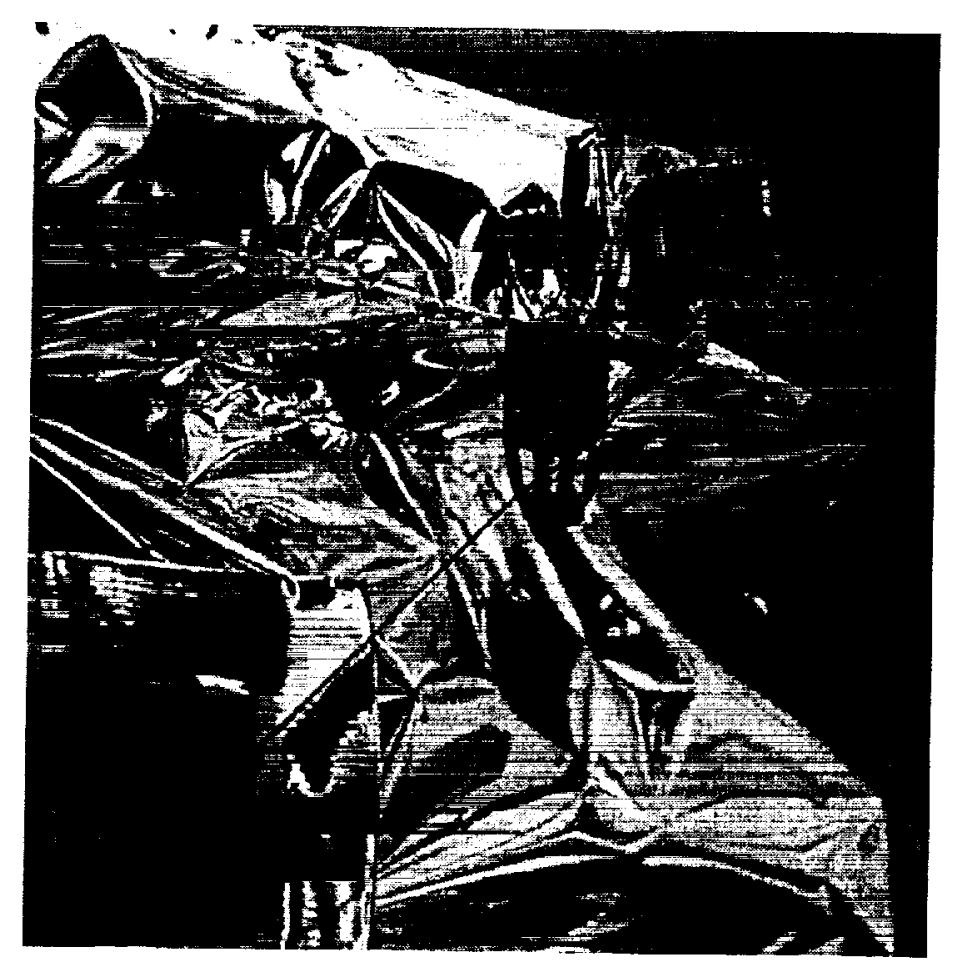

Figure 16 - SSRF attachment 